\title{
Spatiotemporal Monitoring for Deforestation and Forest Degradation Activities in Selected Areas of Khyber Pakhtunkhwa (KPK)
}

\section{Saif ur Rehman Khalid, Mobushir Riaz Khan, Muhammad Usman*, Muhammad Waqar Yasin, Muhammad Shahid Iqbal}

Department of Geo-Informatics, Pir Mehr Ali Shah Arid Agriculture University, Rawalpindi, Pakistan

Email: ^usm123.123@gmail.com

How to cite this paper: Khalid, S. ur R., Khan, M.R., Usman, M., Yasin, M.W. and Iqbal, M.S. (2016) Spatiotemporal Monitoring for Deforestation and Forest Degradation Activities in Selected Areas of Khyber Pakhtunkhwa (KPK). International Journau of Geosciences, 7, 1191-1207. http://dx.doi.org/10.4236/ijg.2016.710089

Received: April 4, 2016

Accepted: October 24, 2016

Published: October 27, 2016

Copyright $\odot 2016$ by authors and Scientific Research Publishing Inc. This work is licensed under the Creative Commons Attribution International License (CC BY 4.0). http://creativecommons.org/licenses/by/4.0/

\begin{abstract}
The global significance of forest ecosystems requires precise determination of the amount of carbon stored in different forest ecosystems. Regular monitoring of forests can aid in designing efficient climate change control strategies at national and global scale specially in reducing emissions from deforestation and degradation strategies. This research is designed to focus on determining deforestation of study area from 2001 to 2011 using Remote Sensing (RS) and Geographic Information System (GIS) techniques. This research provided rate and amount of degradation of forests in the study area and was quite helpful in formulating a strategy to earn carbon credits consistently and, therefore, will help in the uplifting of the standards of local population.
\end{abstract}

\section{Keywords}

Deforestation, Degradation, Carbon Credits, Climate Change

\section{Introduction}

One of the most debated and provocative science issues of 21st century is Global Warming. Report of Intergovernmental Panel on Climate Change (IPCC) on this issue, proclaims that the scientific concerns and suspicions of global warming are fundamentally determined. According to this report, there is $20 \mathrm{~cm}$ rise in sea level and $0.6^{\circ} \mathrm{C}$ rise in global temperature during the last century i.e. 20th century. The IPCC report also suggests that by the end of this century, global temperature could rise by $1.4^{\circ} \mathrm{C}$ to $5.8^{\circ} \mathrm{C}$ and sea level could rise by between $20 \mathrm{~cm}$ and $88 \mathrm{~cm}$ if situation remains unchanged [1]. 
This is not the matter of national interest within the boundary of a country now; rather it is a global responsibility of human kind and all the nations will have to realize it globally and act upon collectively and effectively and should be taken seriously to save our planet [2].

Extensive concern about global climate change has led to attention in reducing emissions of carbon dioxide $\left(\mathrm{CO}_{2}\right)$ and under certain conditions, in counting additional carbon captivated in soils and vegetation as part of encouraging the emissions reductions. Increasing the amount of carbon removed by and stored in forests can be one option for slowing the rise of greenhouse gas concentrations in the atmosphere, and thereby providing possible mitigation of adverse effects of change in climate [3].

According to the Government of Pakistan 4.2 million ha of area is covered by forest in Pakistan i.e., only about 4.8 percent of total land area. Forest area of Khyber Pakhtunkhwa (KPK) is 1.21 million hectares, i.e., 40 percent of total forest area of the country [4].

Forests are an essential part of daily lives of the countryside population living close to forested areas of Khyber Pakhtunkhwa (KPK). Timber, firewood, forest soil, pastures, and raw goods for industries of cottage, medicinal or edible plants and royalty expenses are the main advantages obtained by local people from these forests. Rural livelihood, most sturdily of those at the lowest of the socio-economic scale is affected by degradation of the forests [5].

The basic idea behind REDD is in fact simple, i.e. countries that are prepared and capable of reducing emissions from deforestation should be monetarily compensated for doing so. To curb global deforestation, previous methodologies have so far been not successfully operational owing to lack of any visible monetary benefits to the local populations. However, REDD provides a new structure to permit deforesting countries to halt this historic trend. REDD is chiefly about emissions reductions and could concurrently address climate change as well as sustainable rural development [6].

In order to qualify for earning carbon credits there are certain perquisites that have to be fulfilled such as:

- Stable forest area for a reasonable period of time.

- Deforestation and forest degradation should be calculated.

- The local population should have sustainable livelihoods.

It is, therefore, required to continuously observe numerous changes occurring in the forest areas, to make optimal policies for better utilization of forests. Conventional methodologies such as surveying are not only labor intensive but also costly. Whereas, cutting edge technology of RS and GIS provides us with the capability to efficiently monitor and manage the forests. Advances in RS and GIS data availability, quality, and type can possibly alleviate the current challenges of large-area monitoring and detailed examinations of subtle forest modifications which are the main hindrances in the understanding of the scale and pace of forest change. Digital remotely sensed imagery is now a standard instrument in the collection of the professional forest manager because the relationship of technology and need has finally arisen [7]. 


\section{Statement of the Problem}

Keeping in view the above mentioned issues pertaining to the adverse effects of carbon emissions being accumulated in the environment, it is required to control such emissions. Since the forests act as carbon sinks by absorbing $\mathrm{CO}_{2}$ from the environment, therefore, sustainable management of the forested areas as well as wellbeing of the local populations is needed. The UN's REDD initiative provides options for the regions which have these natural carbon sinks to earn credits from those regions which are causing carbon emissions through their industries. The REDD have certain conditions to be fulfilled before earning the carbon credits. These conditions demand sustainable forest areas as well as providing livelihood to the local populations. This demands regular monitoring of forest areas and assessment of afforestation activities for the preservation from damaging and deforestation.

Essentially the main objective of this study is to provide rate and amount of degradation of forests in the study area and hence to formulate a strategy to earn carbon credits consistently and, therefore, help in the uplifting of the standards of local population.

Therefore, the following goals are required to be achieved by this research.

- Preparation of baseline data for implementation of REDD.

- Land-cover map including deforestation/afforestation estimation maps of the study area.

- How much forest cover changes in the form of deforestation/afforestation in study area has occurred in the last 10 years?

- Comprehensive analysis on the basis of research study of selected forest area of Khyber Pakhtunkhwa province.

\section{Study Area}

The area under study consists of 3 northern districts of KPK province of Pakistan i.e. Kohistan, Shangla and Batgram which include 7 tehsils i.e. Pattan, Bisham, Chakisar, Maroong, Palas, Allai and Batagram, as shown in Figure 1. This area is located in north-western side of Pakistan. Its total area is $7126.2 \mathrm{~km}^{2}$. Its borders meet Kohistan Division to the North, Sawat Division to the West and it is surrounded by Mansehra Division to the East and South.

\section{Methodology}

ASTER images were collected since it has 15 meter spatial resolution (VNIR bands) and 90 meter spatial resolution (Thermal Bands) which is finer as compared to LANDSAT TM data which has 30 meter spatial resolution of visible/infrared range and 120 meter resolution for thermal band. Two datasets of ASTER_14DMO images of year 2001 and 2011 comprising of total 23 images were used (10 images from 2001 and 13 images from 2011). Google Earth Images of study area were used online for hybrid classification since these are very high resolution images and covers different period of time (historical images). So high resolution images i.e. Geo Eye 0.5, Quickbird 0.61 and SPOT 2.5 images of year 2001 and 2011 were used for hybrid classification. Radiometric 


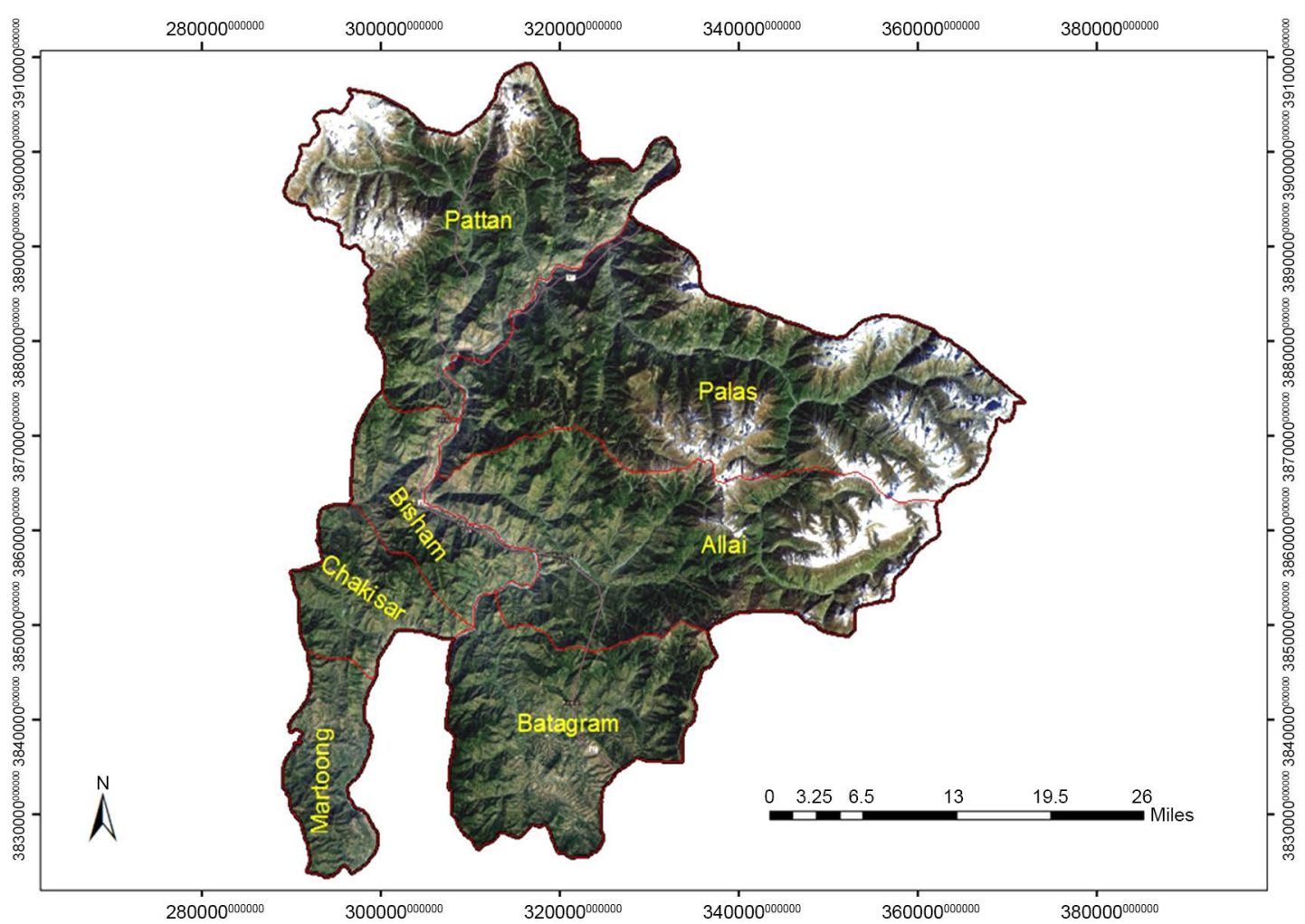

Figure 1. Map of study area.

correction of ASTER images (VNIR) was carried out to derive ecologically relevant vegetation metrics. Top of atmosphere reflectance was calculated to use as the input for the Normalized Difference Vegetation Index (NDVI). Top of atmosphere reflectance corrects for two sets of factors and for this purpose "aster_radiance_vnir_hhn.gmd" model as shown in Figure 2, was used to convert an input visible near-infrared (VNIR) image in scaled radiance (with bands 1 and 2 collected with the high gain setting and band $3 \mathrm{~N}$ collected with the normal gain setting) to true radiance using the unit conversion coefficients and finally converted into top of atmosphere by using graphical model as shown in Figure 3.

- Variations in solar illumination influenced by properties such as the solar elevation angle and earth-sun distance.

- The influence of atmospheric haze and aerosols on the signal detected by the sensor. By correcting for these factors, surface reflectance should characterize the land features themselves.

Change detection in land use and land cover can be done by different ways. Each method has its own advantages and disadvantages. Most effective and simple technique is determining change detection through image classifications. In this process different classes are assigned to the pixels of remotely sensed data. The chief objective of this process is to recognize between different classes of land cover e.g. forest area, bare land, agricultural, vegetation, water bodies and urban area etc.

Change detection in land use and land cover can be done by different ways. Each 


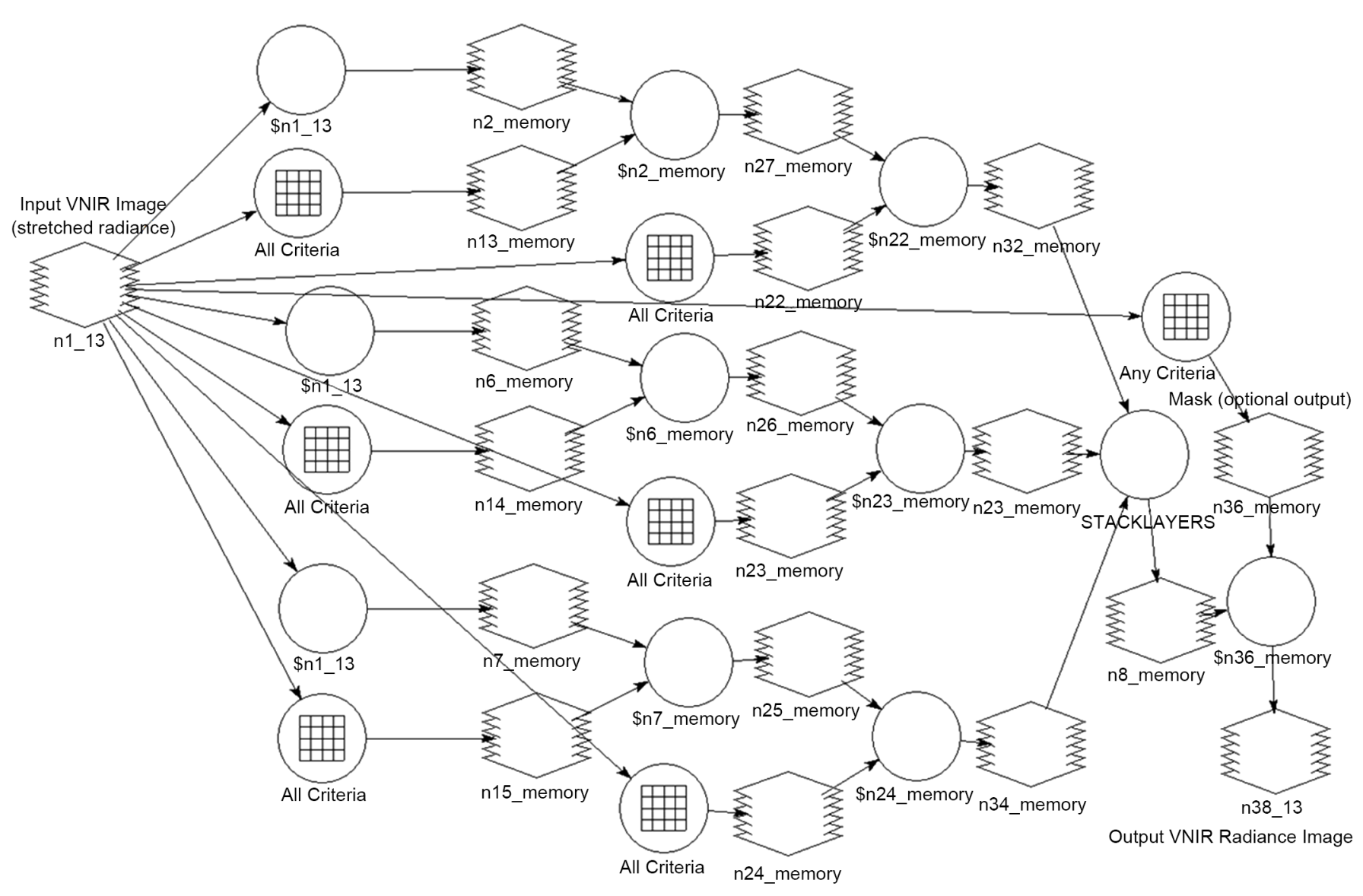

Figure 2. ERDAS graphical model for conversion of sensor DN values to top of atmosphere radiance.

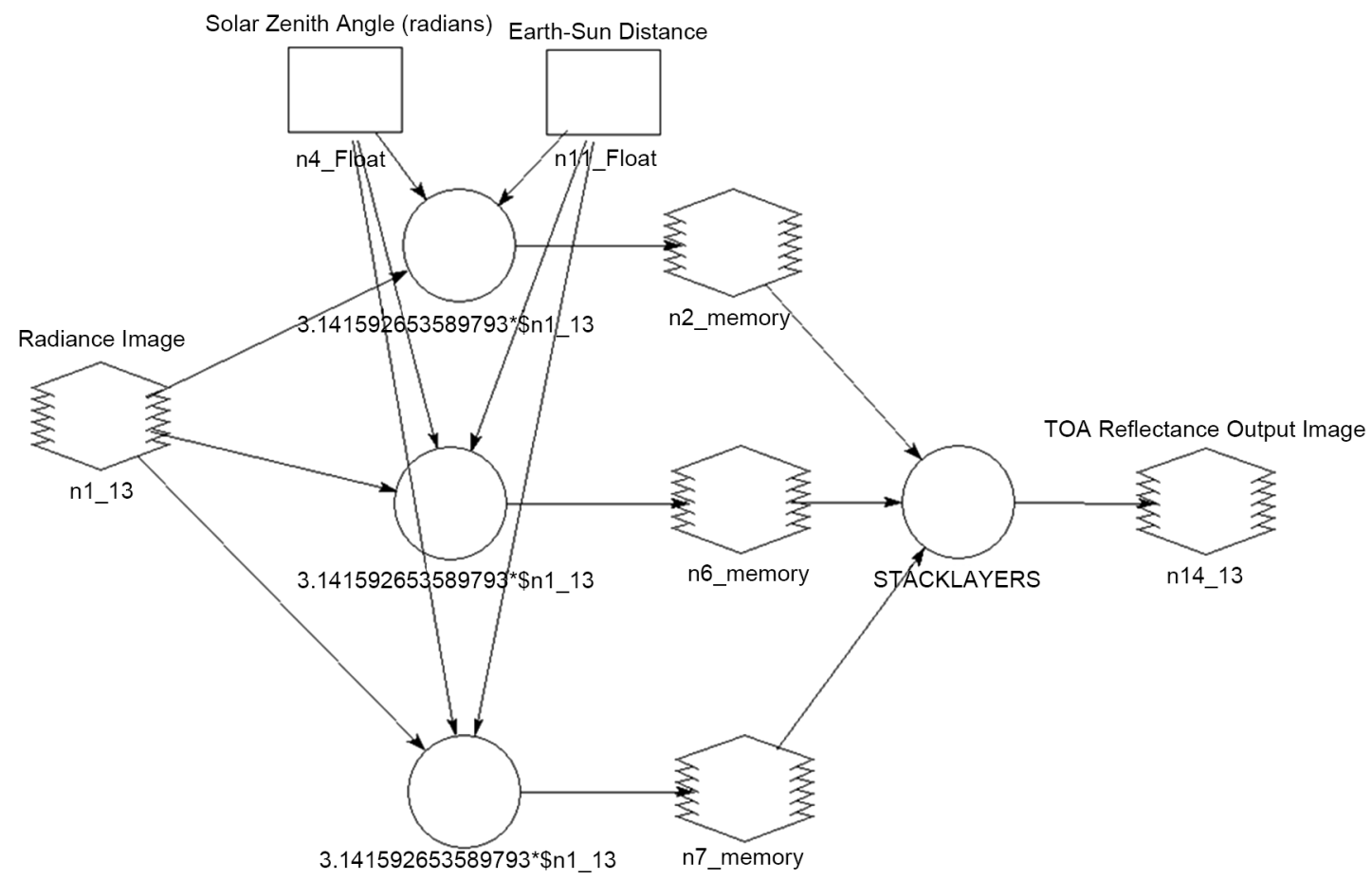

Figure 3. ERDAS graphical model for conversion radiance to top of atmosphere reflectance. 
method has its own advantages and disadvantages. Most effective and simple technique is determining change detection through image classifications. In this process different classes are assigned to the pixels of remotely sensed data. The chief objective of this process is to recognize between different classes of land cover e.g. forest area, bare land, agricultural, vegetation, water bodies and urban area etc.

Change detection in land use and land cover can be done by different ways. Each method has its own advantages and disadvantages. Most effective and simple technique is determining change detection through image classifications. In this process different classes are assigned to the pixels of remotely sensed data. The chief objective of this process is to recognize between different classes of land cover e.g. forest area, bare land, agricultural, vegetation, water bodies and urban area etc.

In classification method used for change detection, each temporal image is categorized independently and then after classification these images are compared to other corresponding images. If the resultant pixels have same land cover class label then it is determined as no change and in the case of difference it is labeled as change [8]. A hybrid classification method was adopted in which first of all unsupervised classification method using ISODATA algorithm was exercised on the datasets of both the years as described below, then a separability analysis was done and final unsupervised classified images were chosen for further process. Now a supervised classification using maximum likelihood was done by taking training samples from high resolution images of Google Earth.

\section{Results and Discussion}

Spatiotemporal analysis exposed a number of output maps at tehsil level Different output maps were produced showing study area, classified maps for the year 2001 and 2011 as shown in Figure 4 and Figure 5 one-to-one; total forest area in 2001 and 2011 as shown in Figure 6 and Figure 7 respectively, forest area, Dense Forest area, agriculture area, total deforestation as shown in Figure 8, total afforestation as shown in Figure 9, deforestation of forest class as shown in Figure 10; afforestation of forest class as shown in Figure 11; deforestation of Dense Forest class as shown in Figure 12; afforestation of Dense Forest class as shown in Figure 13 and finally agriculture area map for the year 2001 and 2011 as shown in Figure 14 and Figure 15 respectively were produced. Also graphical representation of dense forest, forest class and union agriculture class at union level for the year 2001 and 2011.

All these maps and graphs show that over the 10 year period, Deforestation and Forest Degradation occurred considerably largely at the places where population is more. Hence it clearly shows socioeconomic activities linked with deforestation or degradation of forests in the area. Since forest was divided into two classes i.e. Forest and Dense Forest, it has been observed that generally Dense Forests have been converted into forest due to individual cutting of trees and forest class was at some places have been eliminated and converted into bare land class. In general, Dense Forest and forest classes have been reduced and bare land has been increased. 
S. ur R. Khalid et al.

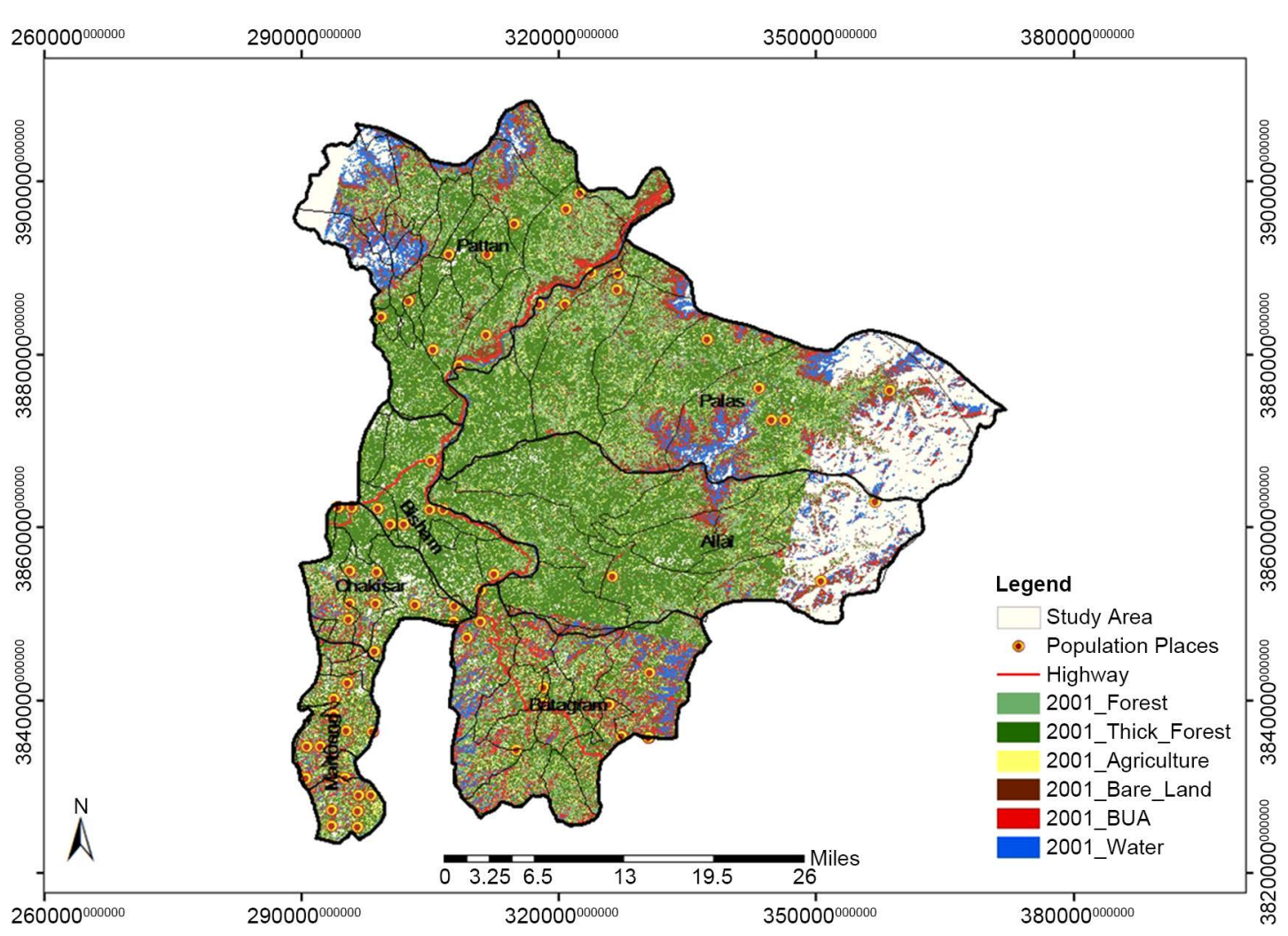

Figure 4. Classified map of 2001.

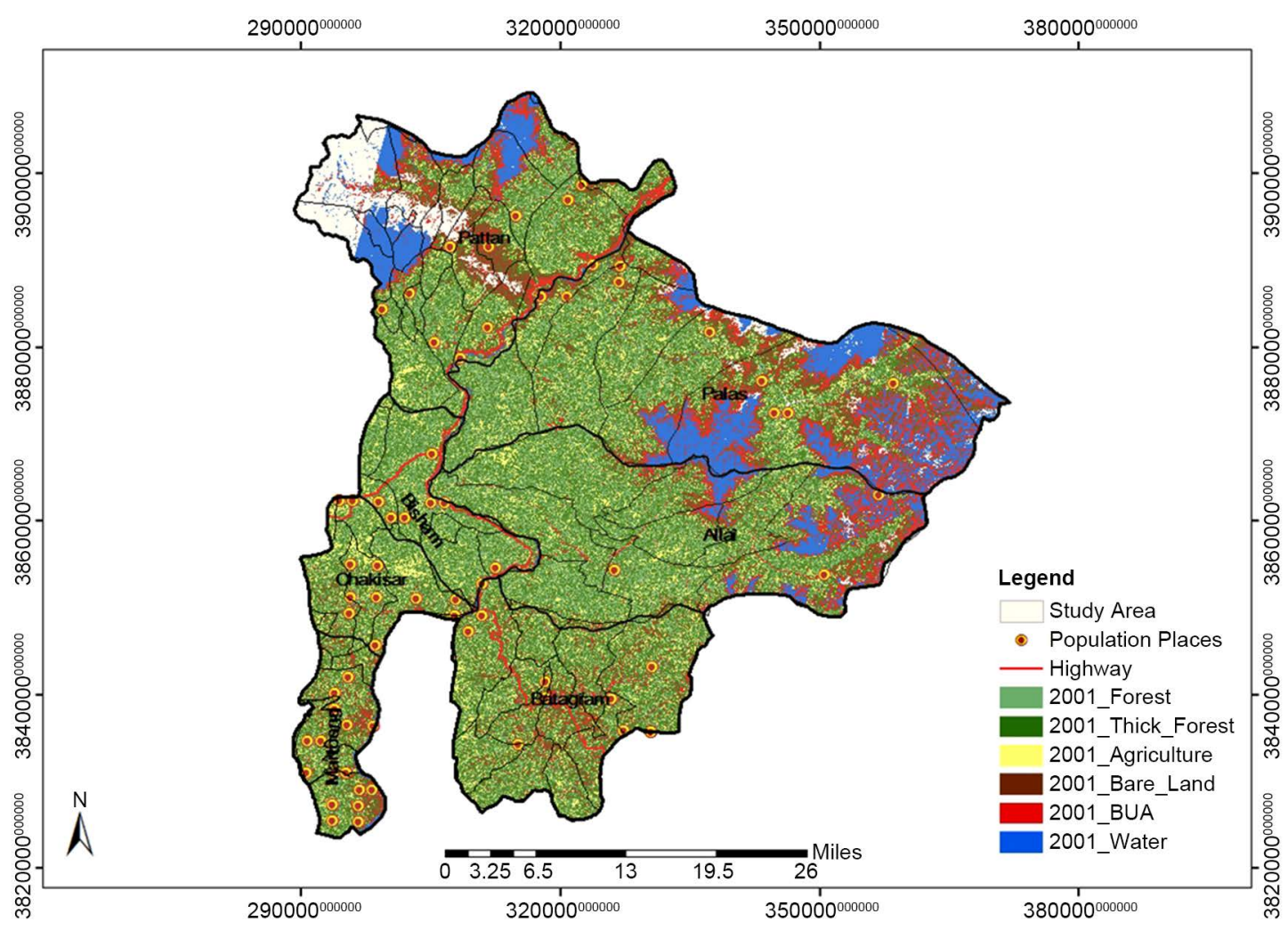

Figure 5. Classified map of 2011. 


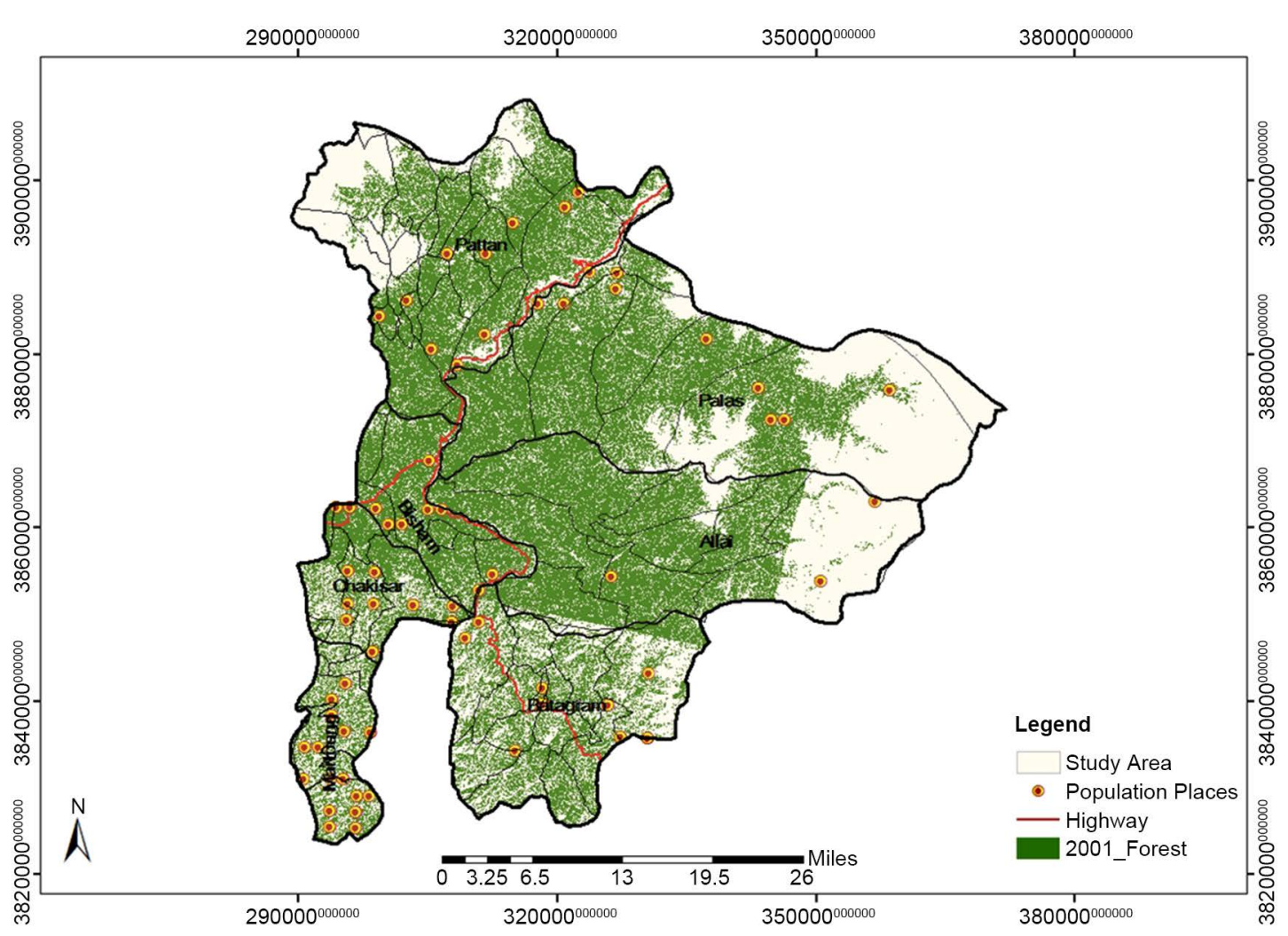

Figure 6. Map of total forest in 2001.

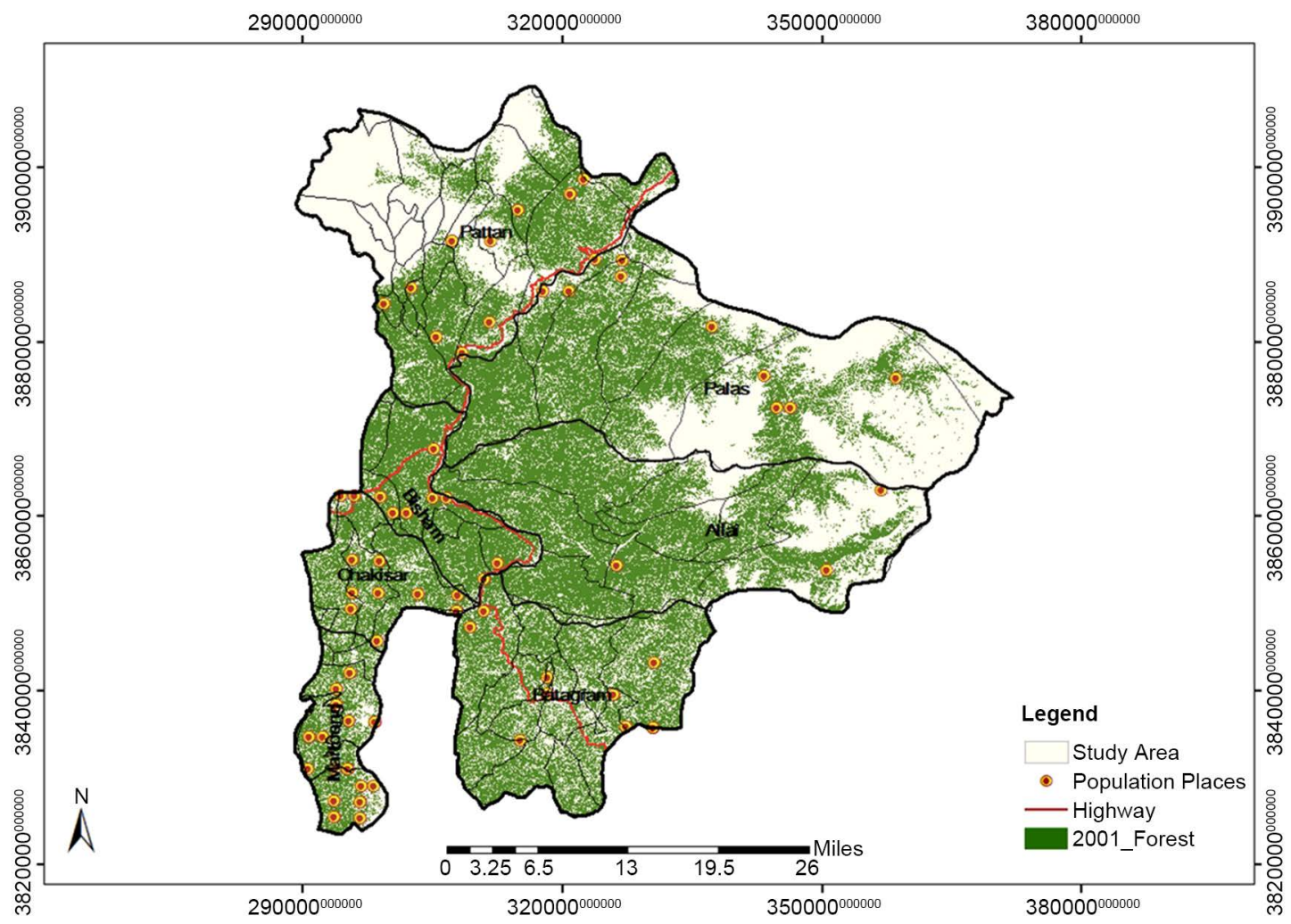

Figure 7. Map of total forest in 2011. 


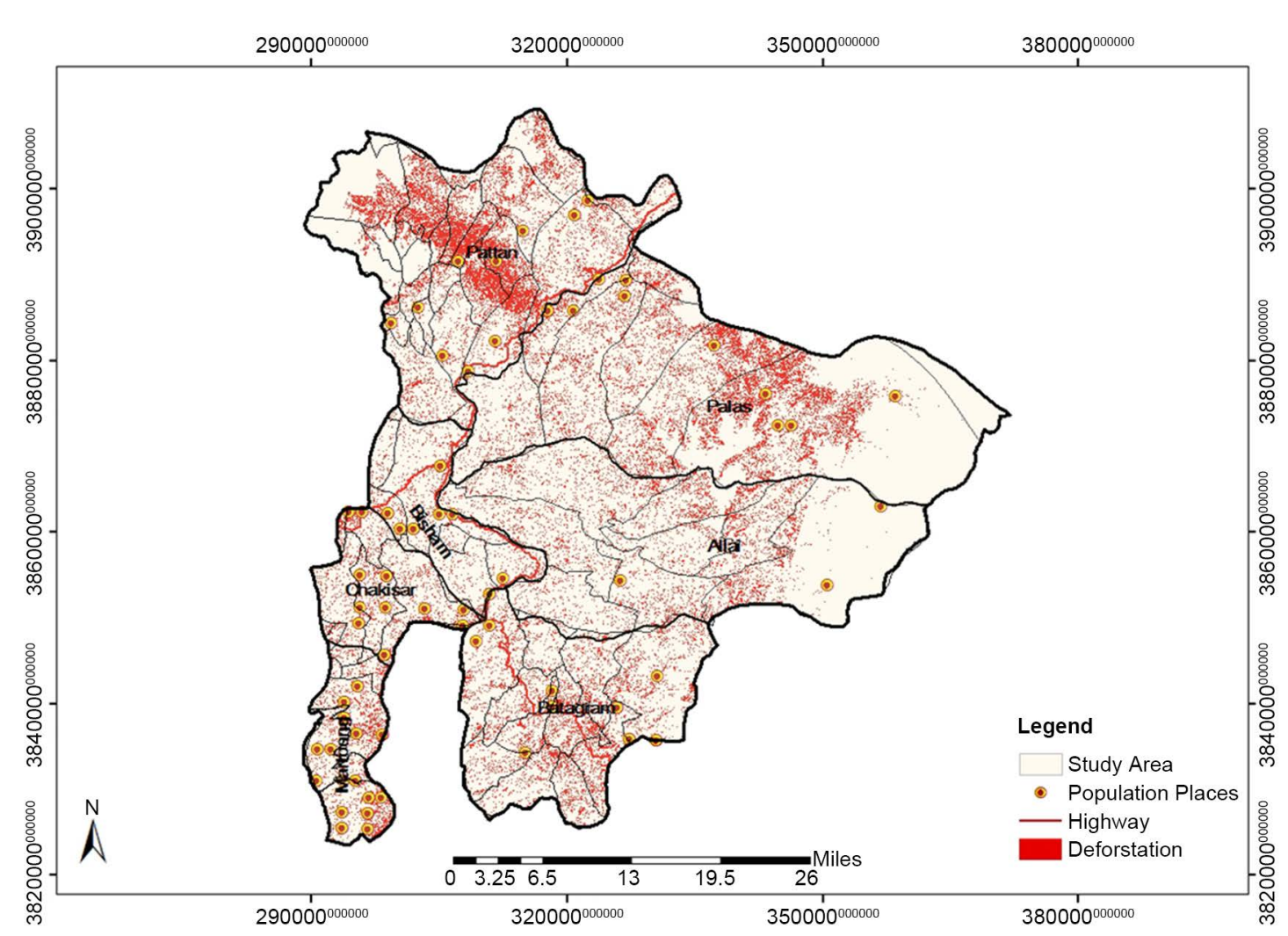

Figure 8. Map of total deforestation.

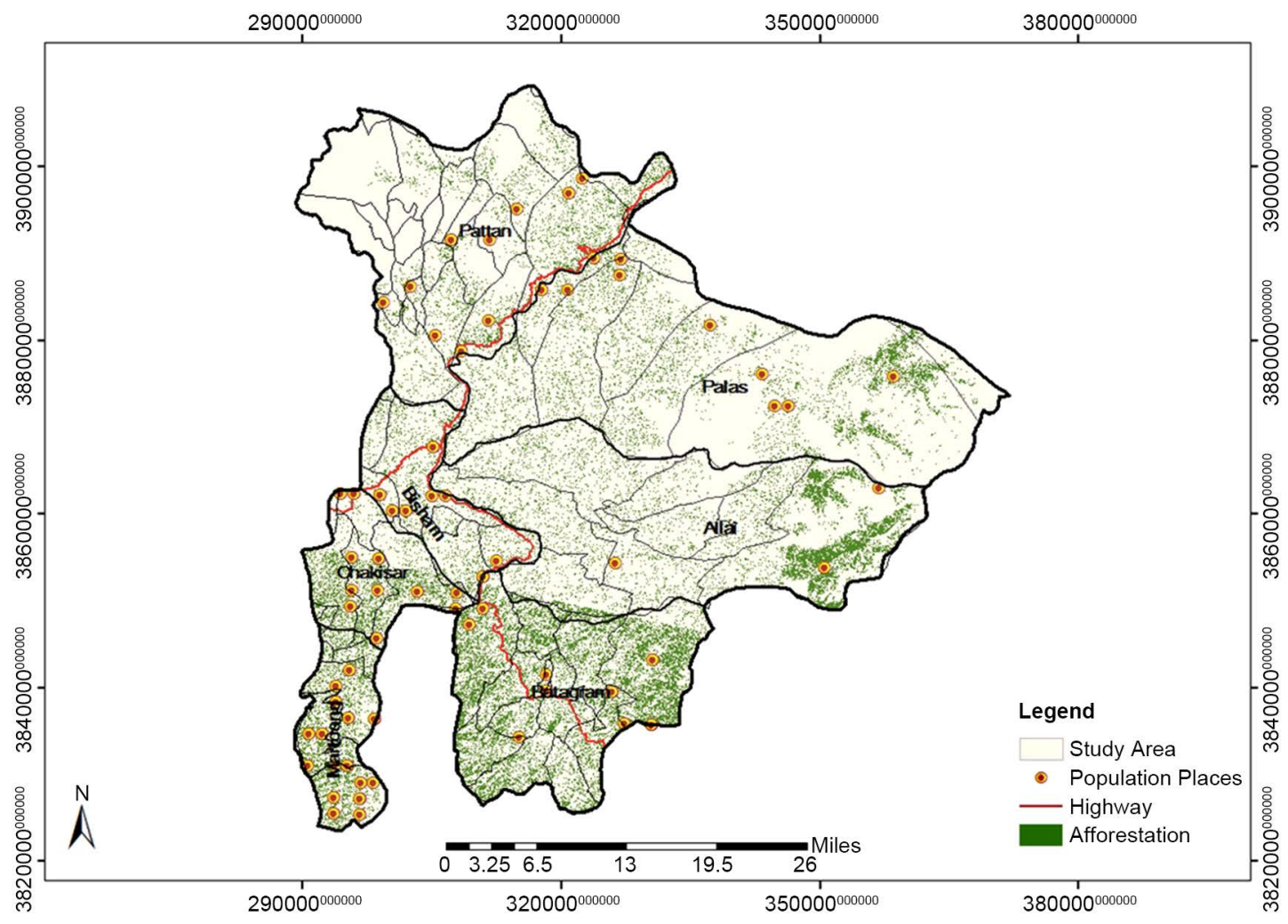

Figure 9. Map of total afforestation. 


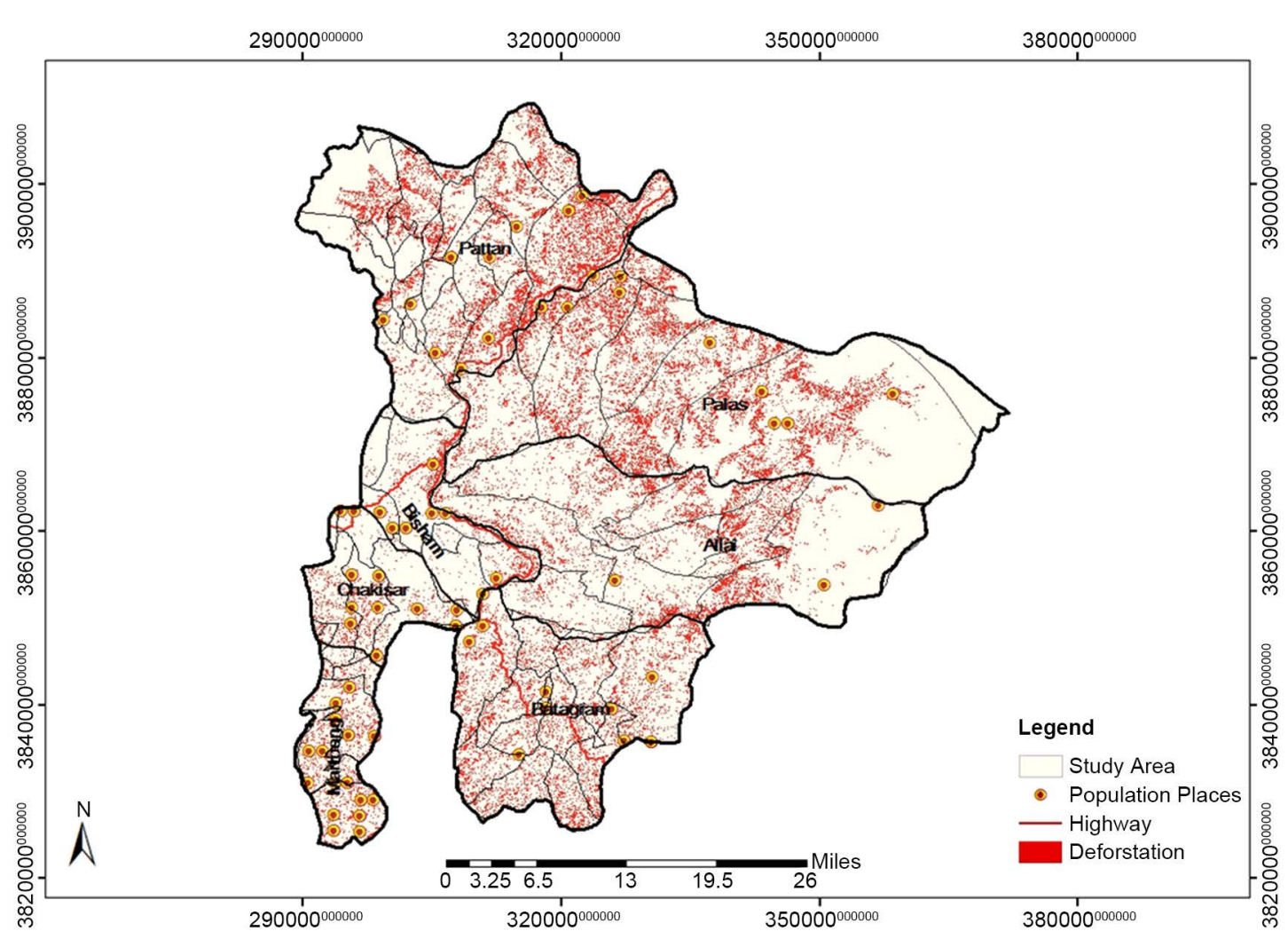

Figure 10. Map of total deforestation (forest class).

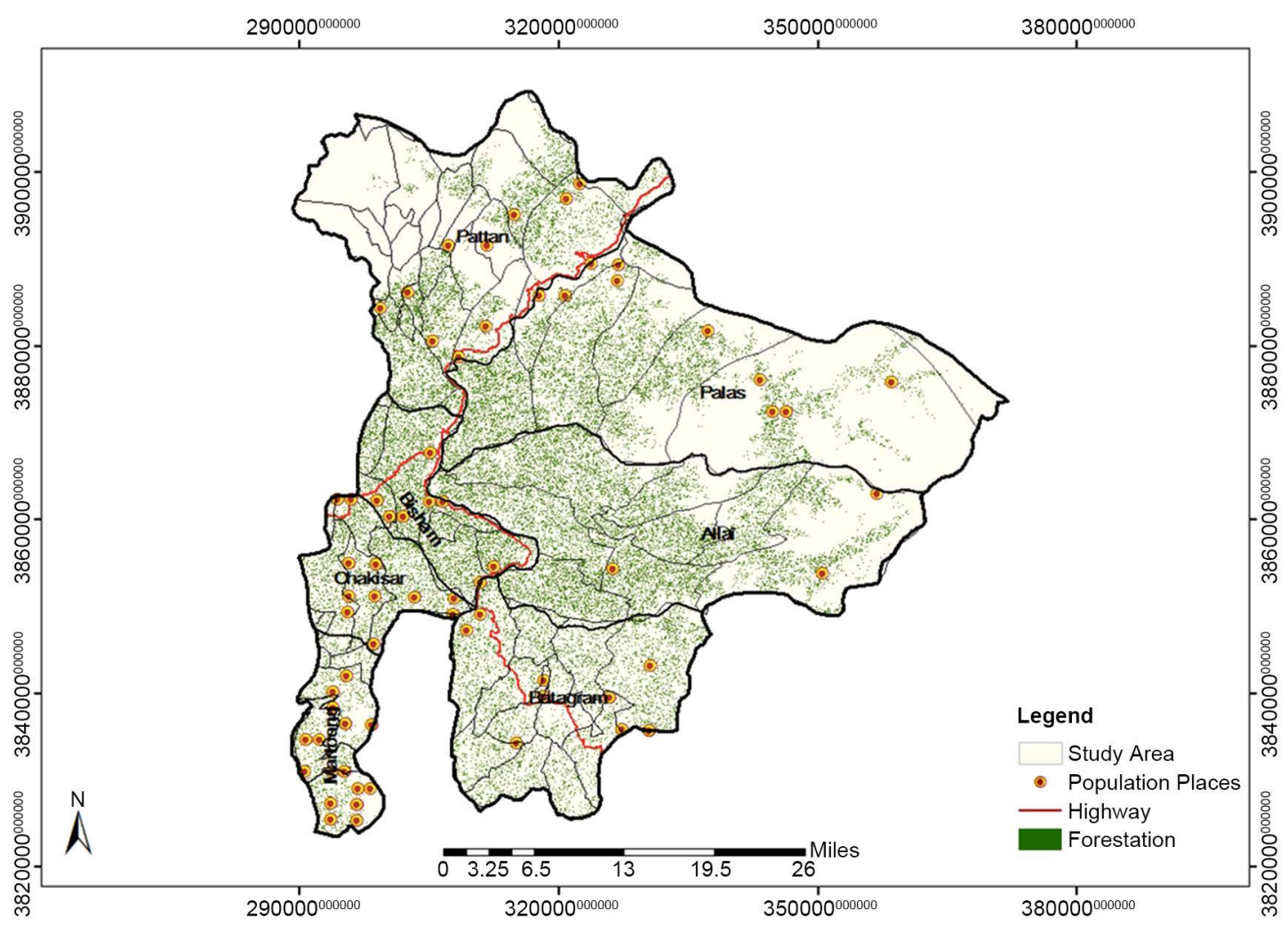

Figure 11. Map of total afforestation (forest class). 


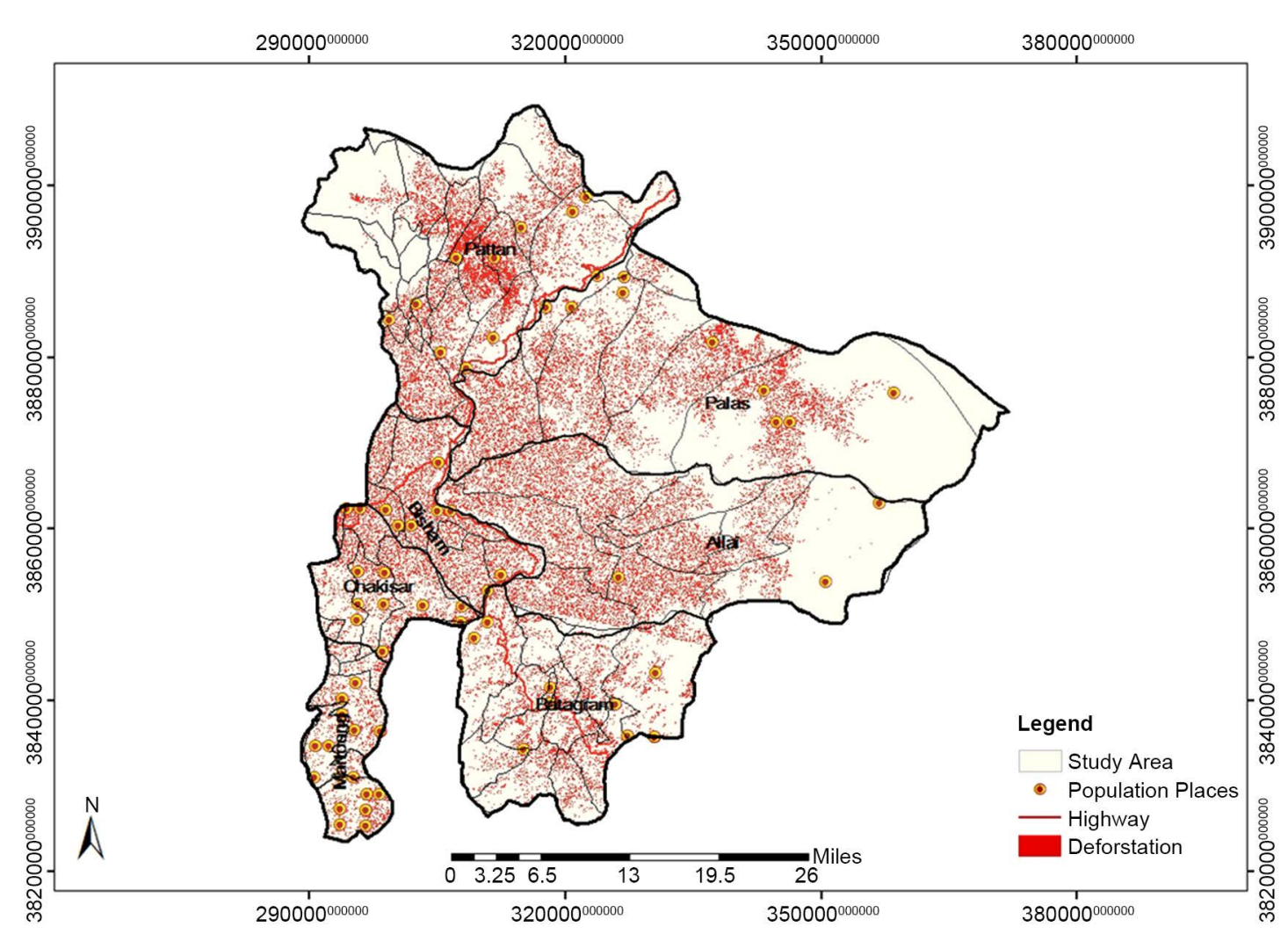

Figure 12. Map of total deforestation (dense forest class).

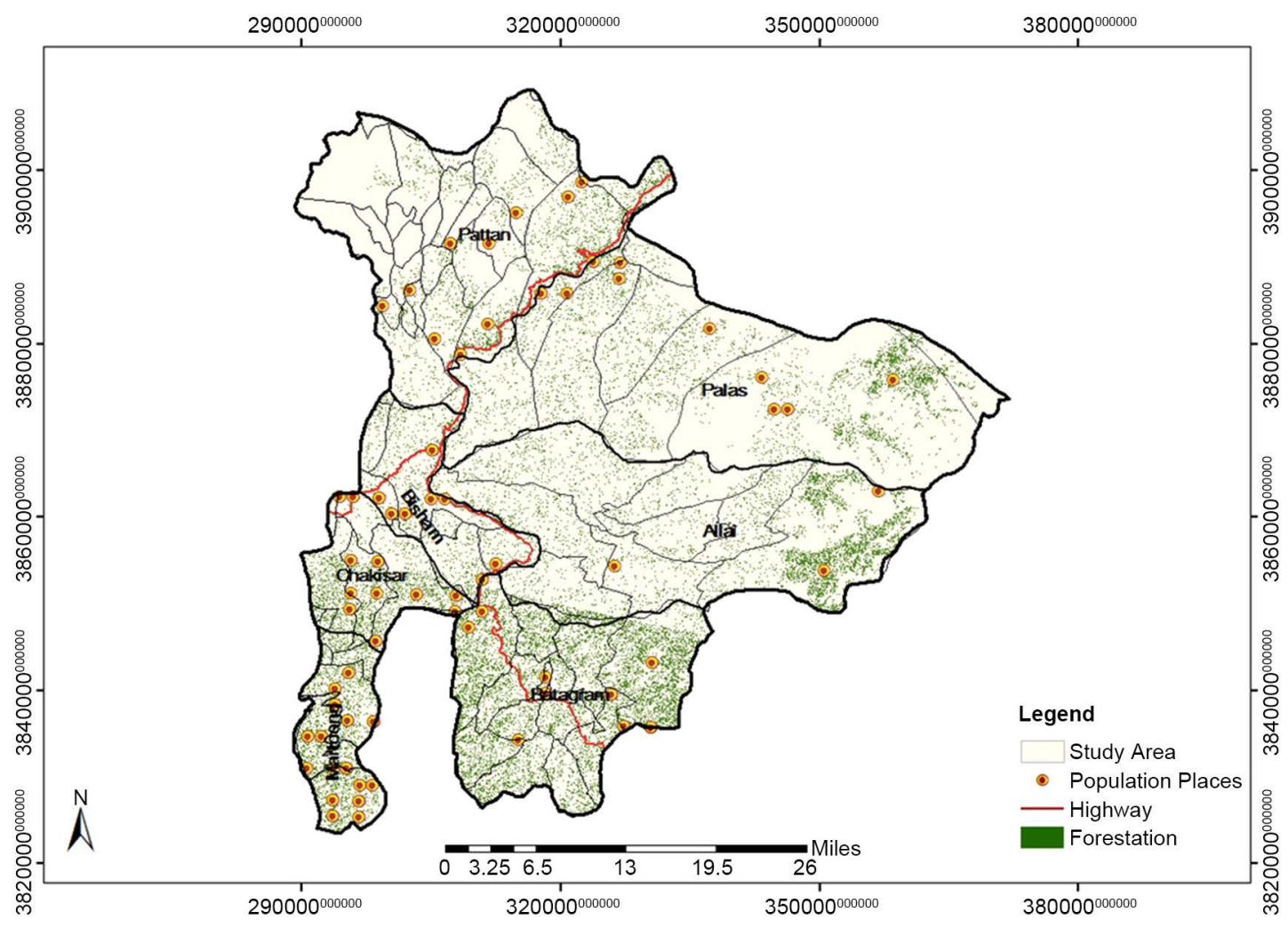

Figure 13. Map of total afforestation (dense forest class). 


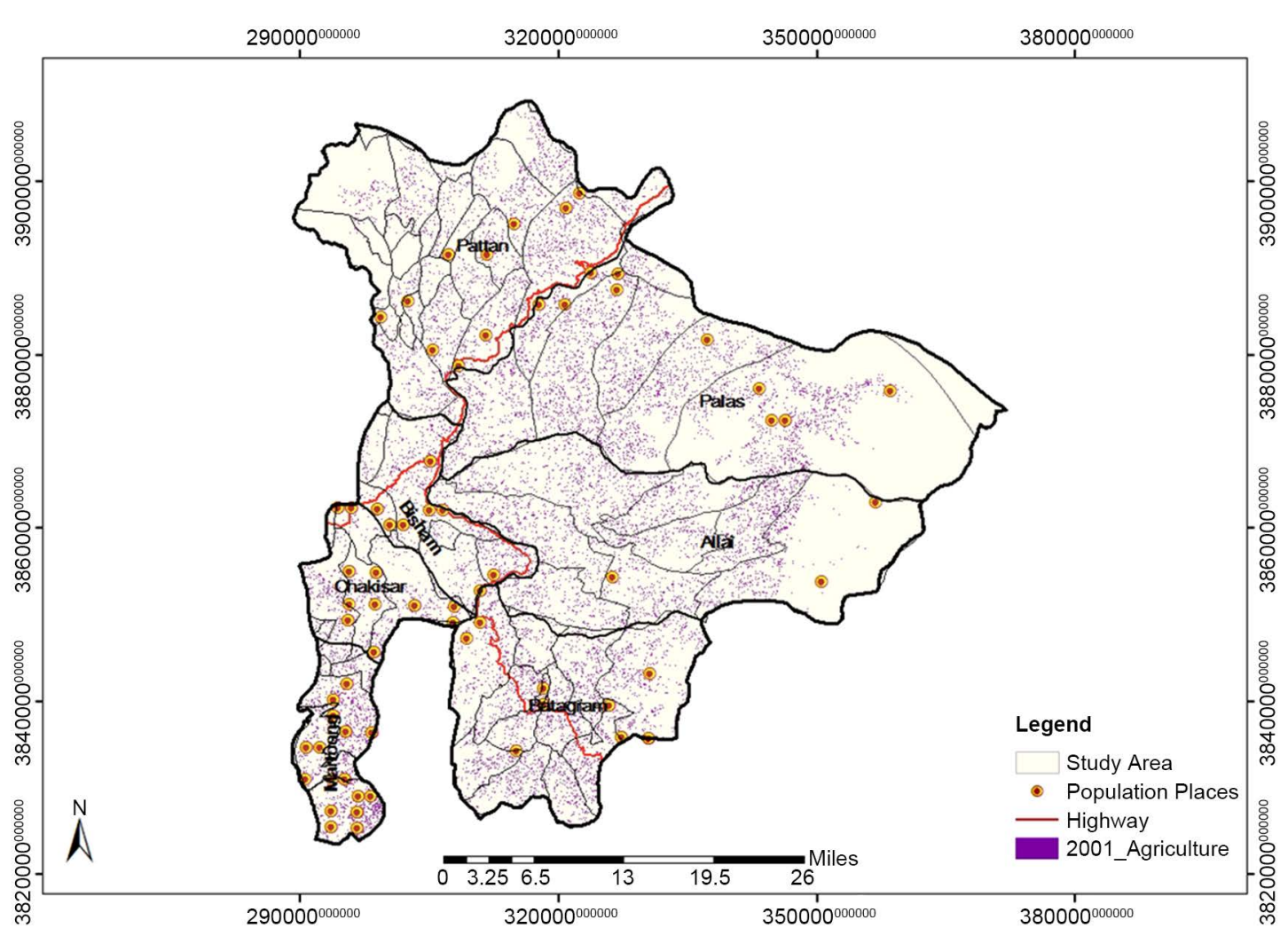

Figure 14. Map of agriculture for 2001.

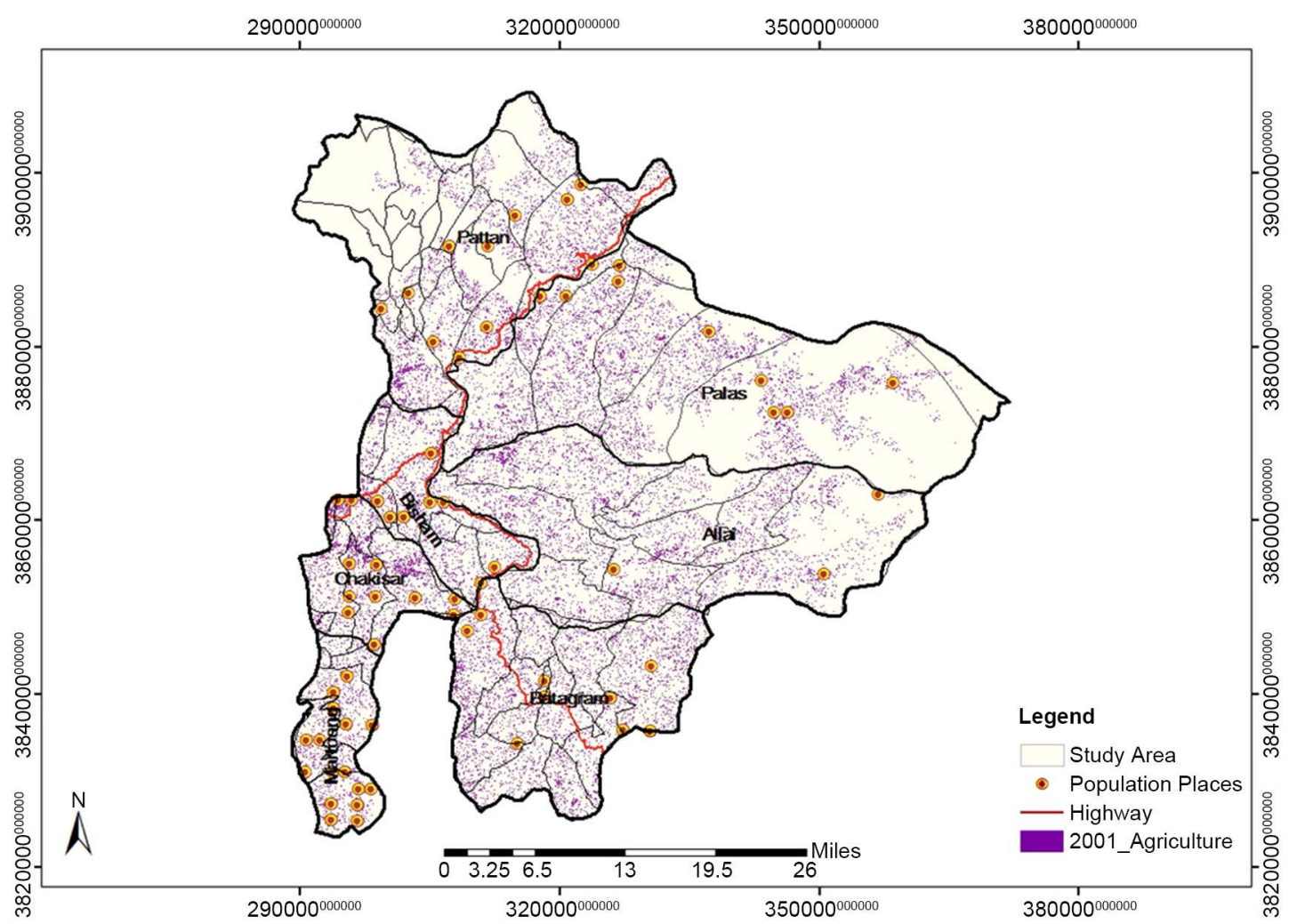

Figure 15. Map of agriculture for 2011. 
Water in the area has also been increased in the area, this is because in datasets of year 2001, Snow was more prominent in the area and since pure snow was eliminated in the images due to the processes applied on the images for atmospheric correction. And this problem was not in the images of 2011 and it shows water and snowy area preserved in classified images as it is, hence it gives wrong impression that what has been increased. So by visual inspection and logic, it has been established that there is generally no change in water class.

Figure 2 shows that the deforestation occurred in all the three studied districts of KPK which needs to be addressed before applying for earning carbon credits under REDD program. The main reasons for deforestation are heavy snowfall, landslides, flash flooding and earthquake. District wise discussion can be divided into three portions emphasizing each district. Kohistan is the most affected region. The area is the least developed area in terms of literacy rate among the entire KPK region. Its literacy rate is only $14.5 \%$. Due to less education, together with less development there are less opportunities of employment are available.

Two tehsils in Kohistan district come under study area i.e. Palas and Pattan. Comparatively Palas has more tendency in deforestation and degradation of forest. Union council areas of Peach Bela, Shaman and Shared in Palas tehsil have been severely affected due to deforestation. However tehsil Pattan shows improvement in forestation. Figure 16 shows that severe deforestation occurred in valleys of Palas tehsil where these forests have been converted to agriculture lands, out of the studied districts, Shangla was mostly affected by 8 Oct 2005 earthquake [9]. The main reasons for deforestation are heavy snowfall, landslides, flash flooding and earthquake.

The local people need to be provided with education, alternate sources of fuel, employment opportunities. Two important economic factors need to be strengthened in the areas which are controlled mining at sites identified by geological survey and forest conservation authorities and establishing fish hatcheries in the cold waters of the area. By stopping illegal mining and establishment of legal mines under the supervision of geological survey and forest conservation authorities will provide employment to the local people along with forest clearing for illegal mines. Similarly the area needs to be provided with expertise for fish nurseries and fish farming. This study also shows that the process of forest degradation is different at different areas. Therefore, it is required to establish the local institutional authorities. Batagram district as shown in Figure 17, although affected badly in 8 October 2005 earthquake, however least affected area as far as deforestation and degradation of forests is concerned.

At some places in tehsil Batagram as shown Figure 18, even one can observe afforestation in many areas especially in areas of union council Batta Mohri, Kuza Banda, Paimal Sharif, Pashora, Raj Dahari, Shamlai, Tarand and Thakot. However, even then a little deforestation can be observed in tehsil Alai. Similar reason as stated above can be sensed in Allai tehsil, where poverty, lack of education, non-availability of energy sources and unemployment in this tehsil is on the increase. Moreover tehsil Allai was also effected severely from 8 Oct 2005 earthquake. 


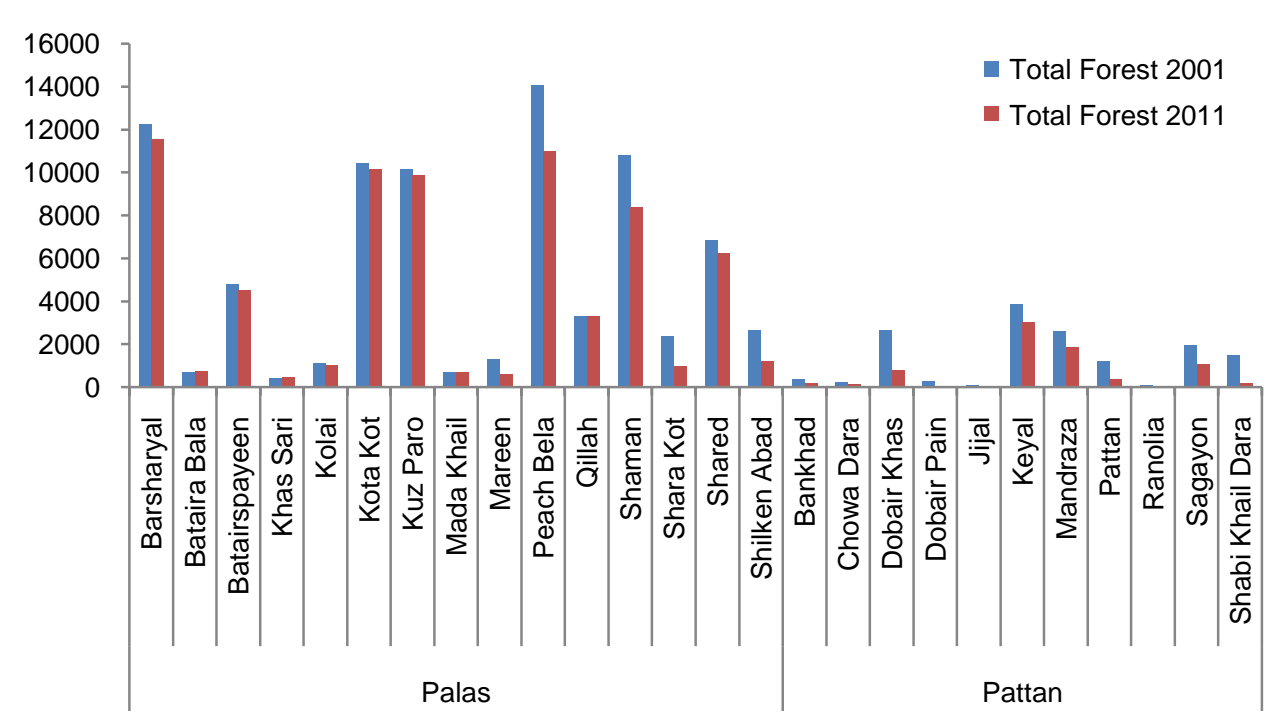

Figure 16. Deforestation and afforestation in Kohistan district.

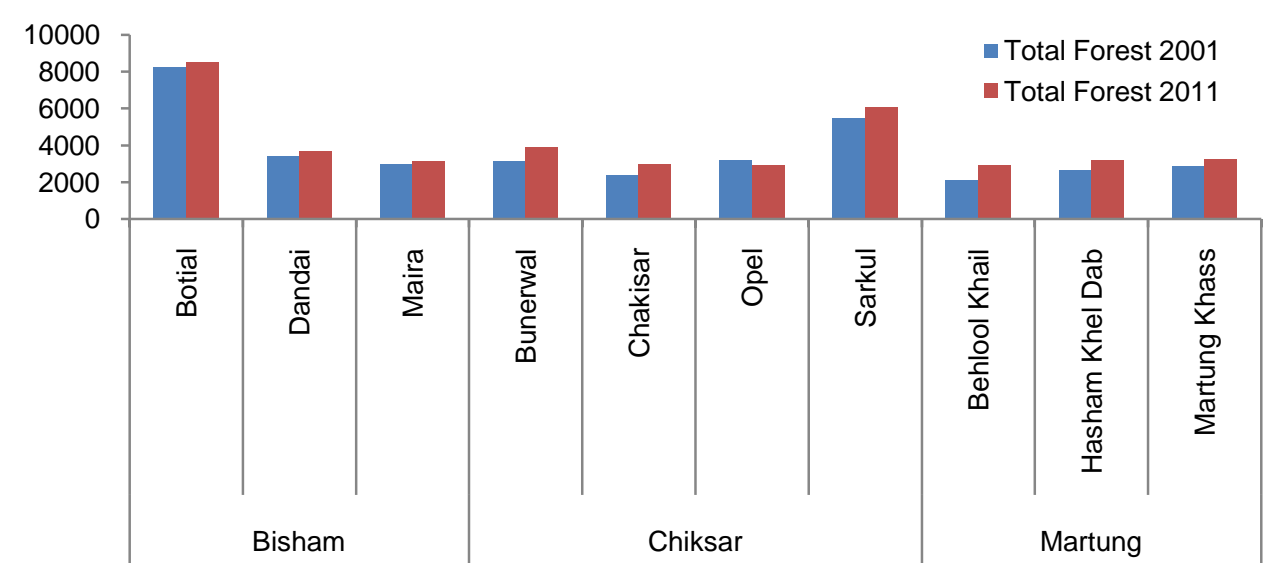

Figure 17. Deforestation and afforestation in Batagram district.

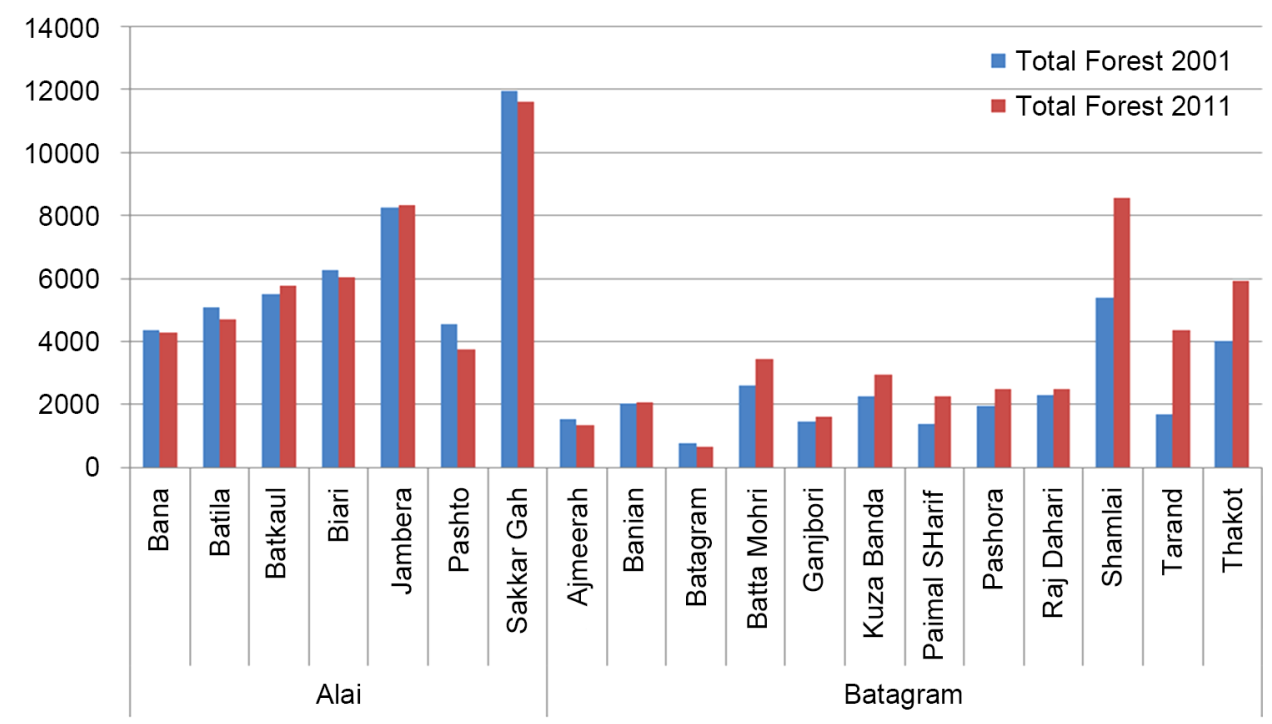

Figure 18. Deforestation and afforestation in Batagram district. 
Accuracy assessment was performed and for this purpose 150 stratified random point throughout classified image of year 2001 were selected. Same point were verified by Google Earth high resolution images of the same area as reference points and then user and producer accuracies were measured, procedure was repeated for classified image of year 2011as shown in Table 1 and Table 2 respectively. The overall accuracies for classified images of year 2001 and year 2011 were achieved which is $93.33 \%$ for both the images. Conditional Kappa for each class for images of year 2001 and 2011 were also calculated as shown in Table 3 and Table 4 respectively.

\section{Conclusion}

On the basis of this research it is concluded that medium resolution remote sensing data provide an efficient means to monitor the forest areas over time, which is a prerequisite to earn carbon credits under REDD program. Hybrid classification aids in identifying features on earth surface by combining the advantages of supervised and unsupervised classifications; atmospheric processing reduces errors and uncertainties in

Table 1. Accuracy assessment of classified image 2001.

\begin{tabular}{cccccc}
\hline Class Names & $\begin{array}{c}\text { Reference } \\
\text { Totals }\end{array}$ & $\begin{array}{c}\text { Classified } \\
\text { Totals }\end{array}$ & $\begin{array}{c}\text { Number } \\
\text { Correct }\end{array}$ & $\begin{array}{c}\text { Producer's } \\
\text { Accuracy }\end{array}$ & $\begin{array}{c}\text { User's } \\
\text { Accuracy }\end{array}$ \\
\hline Water & 10 & 11 & 10 & $100.00 \%$ & $90.91 \%$ \\
Built-up & 7 & 9 & 5 & $71.43 \%$ & $55.56 \%$ \\
Bare Land & 15 & 15 & 13 & $86.67 \%$ & $86.67 \%$ \\
Forest & 36 & 33 & 33 & $91.67 \%$ & $100.00 \%$ \\
Agriculture & 16 & 13 & 13 & $81.25 \%$ & $100.00 \%$ \\
Dense Forest & 66 & 69 & 66 & $100.00 \%$ & $95.65 \%$ \\
Totals & 150 & 150 & 140 & & \\
\hline
\end{tabular}

Overall Classification Accuracy $=93.33 \%$.

Table 2. Accuracy assessment of classified image 2011.

\begin{tabular}{cccccc}
\hline Class Name & $\begin{array}{c}\text { Reference } \\
\text { Totals }\end{array}$ & $\begin{array}{c}\text { Classified } \\
\text { Totals }\end{array}$ & $\begin{array}{c}\text { Number } \\
\text { Correct }\end{array}$ & $\begin{array}{c}\text { Producer's } \\
\text { Accuracy }\end{array}$ & $\begin{array}{c}\text { User's } \\
\text { Accuracy }\end{array}$ \\
\hline Water & 14 & 15 & 14 & $100.00 \%$ & $100.00 \%$ \\
Built-up & 15 & 14 & 13 & $86.61 \%$ & $92.81 \%$ \\
Bare Land & 18 & 17 & 17 & $95.00 \%$ & $100.00 \%$ \\
Agriculture & 15 & 16 & 14 & $95.00 \%$ & $90.91 \%$ \\
Forest & 29 & 30 & 27 & $94.12 \%$ & $90.27 \%$ \\
Dense Forest & 59 & 58 & 55 & $93.27 \%$ & $94.68 \%$ \\
Totals & 150 & 150 & 140 & & \\
\hline
\end{tabular}

Overall Classification Accuracy $=93.33 \%$. 
Table 3. Kappa (K) statistics for classified image 2001.

\begin{tabular}{cc}
\hline Class Name & Kappa (K) \\
Water & 0.9026 \\
Built-up & 0.5338 \\
Bare Land & 0.8519 \\
Forest & 1 \\
Agriculture & 1 \\
Dense Forest & 0.9224 \\
\hline
\end{tabular}

Overall Kappa Statistics $=0.9071$.

Table 4. Kappa (K) statistics for classified image 2011.

\begin{tabular}{cc}
\hline Class Name & Kappa (K) \\
Water & 0.9413 \\
Built-up & 0.92505 \\
Bare Land & 1 \\
Agriculture & 0.9026 \\
Forest & 0.89185 \\
Thick Forest & 0.94264 \\
\hline
\end{tabular}

Overall Kappa Statistics $=0.9280$.

geospatial analysis. The forest areas of KPK have a great potential for earning carbon credits under REDD program. The areas as described in discussion need to be regularly monitored; remedial measure to counter deforestation should be taken; local people should be provided with education; and infrastructure should be strengthened particularly in energy and sanitation (water conservation/purification). The areas of transition (from dense forests to scattered forests) should be monitored and afforestation activities should be conducted in these areas. Illegal forest cuttings should be strictly controlled through strong law enforcement. Urbanization trends in the district of Batagram need to be institutionalized.

\section{Acknowledgements}

The authors thank to Dr. Mobushir Riaz Khan, associate professor at Department of Geo-informatics, Pir Mehr Ali Shah Arid Agriculture University Rawalpindi, Pakistan for his valuable scientific and technical support, also for providing data set for this research.

\section{References}

[1] Solomon, S., et al. (2007) Contribution of Working Group I to the Fourth Assessment Report of the Intergovernmental Panel on Climate Change. 
[2] Maslin, M. (2004) Global Warming: A Very Short Introduction. Oxford University Press Inc., New York.

[3] Gorte, R.W. (2009) Carbon Sequestration in Forests. Congressional Research Service.

[4] Shahbaz, B., Ali, T. and Suleri, A.Q. (2004) Critical Analysis of Forest Policies of Pakistan: Implications for Sustainable Livelihoods. University of Agriculture, Faisalabad, Pakistan. Sustainable Development Policy Institute (SDPI), Islamabad, Pakistan.

[5] Khan, S.R. and Naqvi, A. (2000) The Environment-Poverty Nexus: An Institutional Analysis. United Nations Development Programme, The Pakistan Planning Commission, Islamabad, Pakistan.

[6] Parker, C., Mitchell, A., Trivedi, M. and Mardas, N. (2008) The Little REDD Book. Global Canopy Foundation, UK.

[7] Rogan, J. and Miller, J. (2006) Integrating GIS and Remotely Sensed Data for Mapping Forest Disturbance and Change. Understanding Forest Disturbance and Spatial Pattern: Remote Sensing and GIS Approaches, 133-172.

[8] Zhang, S.Q. and Xu, L. (2008) The Comparative Study of Three Methods of Remote Sensing Image Change Detection. The International Archive of Photogrammetry, Remote Sensing and Spatial Information Science, XXXVII, Part b7, Beijing.

[9] NDMA (2007) 2007 Districts Disaster Risk Management Plan, Building Enabling Governance and Institutions for Earthquake Response (BEGIN-ER). ERRA 2007.

\section{Submit or recommend next manuscript to SCIRP and we will provide best service for you:}

Accepting pre-submission inquiries through Email, Facebook, LinkedIn, Twitter, etc.

A wide selection of journals (inclusive of 9 subjects, more than 200 journals)

Providing 24-hour high-quality service

User-friendly online submission system

Fair and swift peer-review system

Efficient typesetting and proofreading procedure

Display of the result of downloads and visits, as well as the number of cited articles

Maximum dissemination of your research work

Submit your manuscript at: http://papersubmission.scirp.org/

Or contact ijg@scirp.org 